\section{Ebenezer Society: A Corporate Networking Ethics Committee}

\section{BRUCE PEDERSON}

Ebenezer Society, Minneapolis, Minnesota, is an affiliate of Lutheran General Health System and a social ministry of the Evangelical Lutheran Church in America. Its mission is "to make the lives of older people as independent, healthful, meaningful and secure as possible." This mission is accomplished through a continuum of care, including housing, healthcare facilities, community services, transportation, a center for aging, and several partnerships. Based on a preface to ethical decision making developed by the spiritual care committee of the board of directors that clearly affirms the "right of self-determination for its residents/patients," Ebenezer has created a corporate ethics committee to act as a resource to residents, families, staff and employees and to help provide guidance to the organization.

The ethics committee functions as a network in that members of the committee are selected to represent one or more areas within the Ebenezer Society and include the chair of the spiritual care committee of the board, President/ CEO, Corporate Medical Director, Corporate Director of Pastoral Care, V.P. for Quality Development, a representative from housing, a representative from community services, a representative from the legal profession (not Corporate Council), a specialist from the field of medical ethics, and a representative from each healthcare facility and a discipline (i.e., administrator, chaplain, social worker, director of nursing, and recreation therapy). Residents, family members, and employees are encouraged to raise ethical issues through contacting this conduit. However, the existing structure for raising such concerns at each site is to be utilized first (going to the head nurse, chaplain, administrator, etc.). The committee exists to support and assist those structures, not to go around them.

The ethics committee meets every other month. A case is reviewed from a different division or facility of Ebenezer at each meeting. These cases test out policies and assist in the learning process.

A current case usually is reviewed by gathering the significant and involved persons at the scene, not by formally presenting a case to the whole committee. Care team members and committee representatives meet with family and the client (if appropriate) to offer an opportunity to discuss in depth the ethical issues surrounding the case and to help explore the ethical questions. The Corporate Medical Director, Chaplain, and Director of Nursing have usually been representatives from the corporate committee. To this group is added family members or guardian, nurses, social workers, and others intimately involved with the resident and family. The physician involved is invited but usually unable to attend. If a change in the plan of care is suggested, this is referred back to the attending physician and resident and/or surrogate decision maker. 